
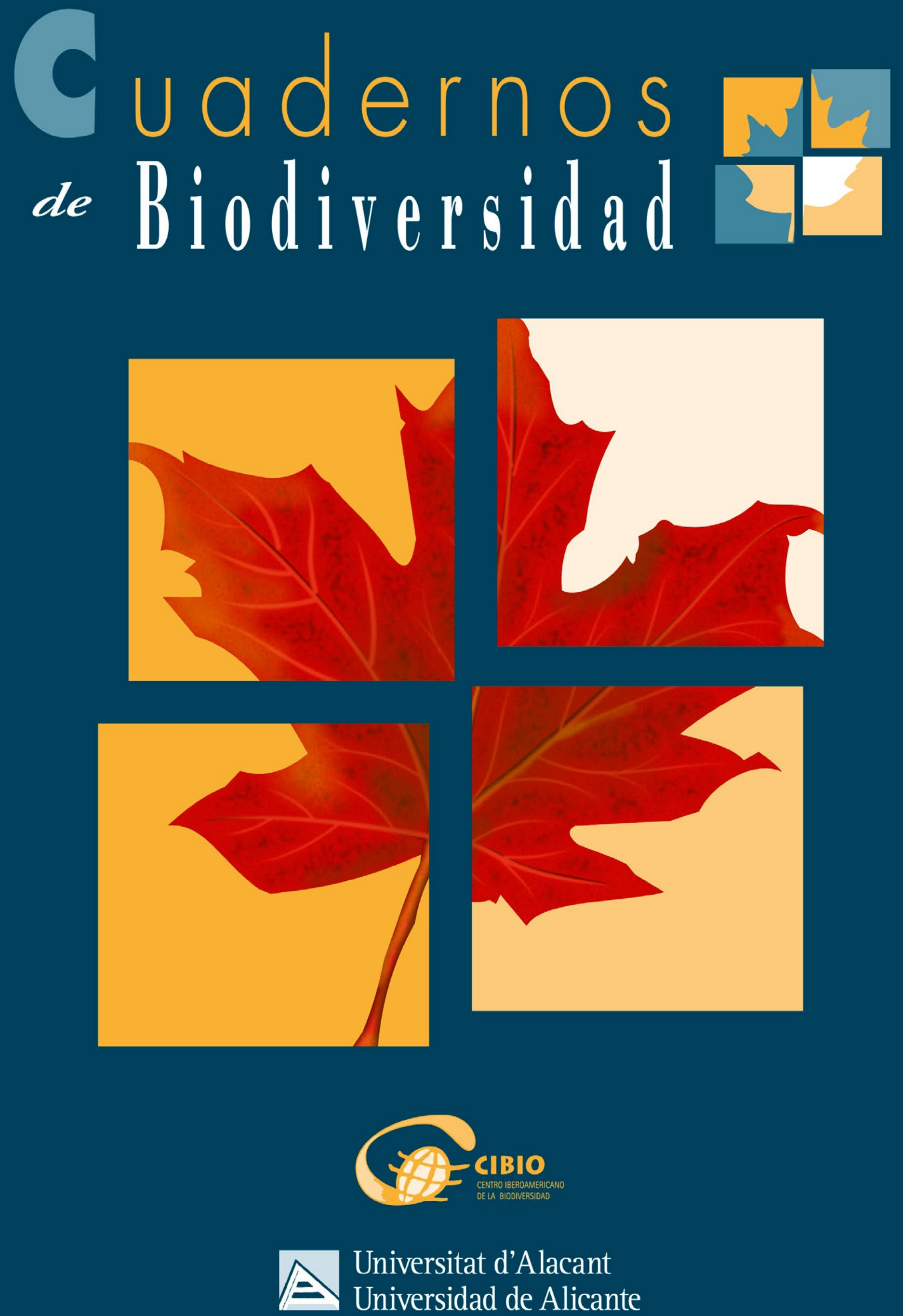


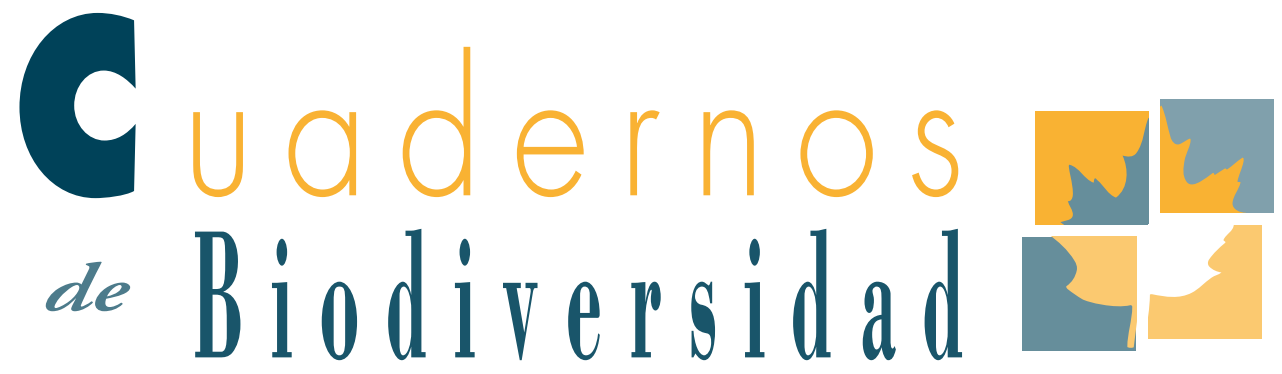

www. cuadernosdebiodiversidad.org

\section{El género Copestylum Macquart, 1846 (Diptera, Syrphidae) en la Reserva de la Biosfera "Barranca de Metztitlán",} México Copestylum Macquart, 1846 (Diptera, Syrphidae) genus in the Biosfere Reserve "Barranca de Metztiflán", México

\section{Ana Paola Martínez-Falcón ${ }^{1}$ y M. Ángeles Marcos-García ${ }^{2}$}

i Centro de Investigaciones Biológicas, Instituto de Ciencias Básicas e Ingeniería, Universidad Autónoma del Estado de Hidalgo. Carretera Pachuca-Tulancingo km 4.5, Mineral de la Reforma, C.P. 42 i 84, Hidalgo, México

2 Instituto de Investigación CIBIO (Centro Iberoamericano de la Biodiversidad), Universidad de Alicante, Campus Universitario San Vicente del Raspeig, 03690, Alicante, España

\section{RESUMEN}

En este trabajo, presentamos una clave para la identificación de especies de sírfidos del género Copestylum asociados a cactáceas en descomposición. Estudiamos la morfología de 12 especies de adultos que fueron criados de muestras colectadas en cactáceas en descomposición dentro de la reserva de la biósfera "Barranca de Metztitlán" en Hidalgo,
México. La clave está acompañada de fotografías de los caracteres diagnósticos de los ejemplares adultos estudiados. También presentamos una tabla que sintetiza información de la relación entre estos sírfidos y sus plantas hospederas.

Palabras clave: moscas de las flores, cactáceas, sírfidos adultos, matorral crasicaule, clave de identificación, Hidalgo. 


\section{ABSTRACT}

In this work, we present a simplified and illustrated identification key of syrphid species of the genus Copestylum, associated with decaying tissues of Cactaceae. We studied adult morphology of 12 reared Copestylum species from samples collected within the "Barranca de Metztitlán" Biosphere Reserve, Hidalgo, Mexico. We provide photographs of the adults of all the studied species and also details of the most important morphological structures. A table summarizing the relation hoverfly/host plant is also provided.

Key words: hoverflies, host plant, cactaceae, adults, scrublands, identification key, Hidalgo.

Las especies del género Copestylum Macquart, 1846 son dípteros pertenecientes a la familia Syphidae con una gran diversidad en cuanto a formas y adaptaciones de vida larvaria, siendo también muy llamativa la variabilidad de coloración, diseño corporal, tamaño, morfología y hábitos de vida de los adultos. Las especies de este género sólo viven en el continente Americano y es uno de los géneros neotropicales de sírfidos más diversos, del que se conocen más de 400 especies, quedando aún muchas por descubrir (Ricarte et al., 2015). Las larvas son saprófagas y se alimentan de los microorganismos procedentes de la materia orgánica en descomposición, pudiéndose desarrollar en una amplia gama de sustratos vegetales y de microhábitats, como son el agua acumulada en las brácteas de bromelias, en pétalos o sépalos de flores, en el interior del tronco de bambú, en tallos y frutos en descomposición. México es uno de los países con mayor diversidad en especies de este género, especialmente las de los grupos cuyos estados inmaduros están estrechamente asociados a los ágaves y a las diferentes especies de cactáceas donde se desarrollan sus larvas (Rotheray et al., 2007). Estas especies pueden encontrarse tanto en ecosistemas extremadamente áridos (Rotheray et al., 2009), como el que nos ocupa, como en los bosques húmedos de niebla del continente americano (Rotheray et al., 2007).
El género Copestylum es de una gran importancia ecológica debido a que participan en diferentes servicios ecosistémicos. Uno de los ya constatados es que sus larvas saprófagas contribuyen significativamente a la descomposición de tejidos vegetales, como es el caso de las Cactaceae y Agavaceae, ayudando así al reciclaje de nutrientes en zonas semiáridas de México (Martínez Falcón et al., 2010; 2011a; 2012). En el tracto digestivo de sus larvas viven bacterias que les ayudan en el proceso de descomposición de los sustratos vegetales en los que viven por lo que esta estrecha relación con la microbiota intestinal es clave en los ciclos de nitrógeno en estas zonas semiáridas (Martínez-Falcón et al., 2011b). Los adultos son insectos voladores, heliófilos y frecuentan las flores de un amplio rango de familias botánicas (Marcos-García y Pérez-Bañón, 2002) de las que se alimentan de polen y néctar, recursos que precisan para su maduración sexual y para obtener la energía necesaria para realizar su característico vuelo cernido.

Rotheray et al. (2009) hacen una revisión exhaustiva de las especies de Copestylum criadas en cactáceas y agaváceas, proporcionando una clave de identificación de sus estados inmaduros y datos sobre los hábitos alimenticios en relación a las modificaciones en el aparato bucal de las larvas. Los principales grupos que se reconocen son: Apiciferum, Isabellina, Dispar y Marginatum. En dicho trabajo los autores distinguen tres tipos de hábitos alimenticios de acuerdo a la consistencia del tejido nutricio en el que se desarrolle la larva: filtrador, succionador y triturador. Algunas larvas son capaces de desarrollarse en tejido firme de los cactus, otras poseen adaptaciones para la filtración de material líquido y un tercer grupo presenta características mixtas.

Los ecosistemas semiáridos mexicanos constituyen un paisaje peculiar con un gran número de endemismos locales entre sus especies de cactáceas (Bravo-Hollis, 1978), por lo que es de gran interés conocer las especies de insectos que se encuentran asociadas a estas plantas. En este trabajo se indican las especies de Copestylum cuyas larvas se desarrollan en los tejidos de cactáceas en descomposición de 
la reserva de la biosfera "Barranca de Metztitlán", estado de Hidalgo, en el centro de México. Este paraje fue decretado reserva en el ańo 2000 debido a su riqueza en especies animales y vegetales y al al to número de especies endémicas de cactáceas considerándose un refugio pleistocénico y constituye una extensión del desierto de Chihuahua (CONANPSEMARNAT, 2003). En este territorio, las especies de cactáceas que se encuentran principalmente son Isolatocereus dumortieri (Scheidw) Backeb, Opuntia ficus-indica (L.) Mill, Myrtillocactus geometrizans (Mart. ex Pfeiff.) Console y Cylindropuntia tunicata (Lehm.) F.M.Knuth, por lo que nuestro estudio contribuye a facilitar el reconocimiento, y por tanto el estudio, de las especies de adultos de Copestylum asociadas a estas cactáceas. Por ser los adultos insectos vistosos, de fácil observación sobre las flores y poseer la mayor parte de sus especies un tamaño y características apropiadas para su reconocimiento $d e$ visu, se pensó en la elaboración de la clave de iden- tificación de las especies del género Copestylum que viven y se desarrollan en las cactáceas de la Barranca de Metztitlán, para que pueda ser de utilidad en futuros estudios de biodiversidad, ecología y biología de las interacciones sírfido-cactácea en esta reserva de la Biosfera. En la clave se ha seguido la terminología de Thompson, 1999.

Para ello, se realizó un muestreo sistemático durante dos ańos de estudio (2005 y 2007). En el mapa 1 se aprecian los seis puntos de muestreo fijados en un matorral crasicaule natural y otro perturbado debido al manejo agropecuario con ganado ovino. En cada uno de los seis puntos se delimitó una parcela de $20 \mathrm{~m}$ x $5 \mathrm{~m}$ dentro de la cual se llevó a cabo una búsqueda directa de muestras de cactáceas en descomposición de diferentes especies. Para mayor información del diseño experimental, consultar Moreno et al. (2007) y Martínez et al. (2011a).

\section{Study area}

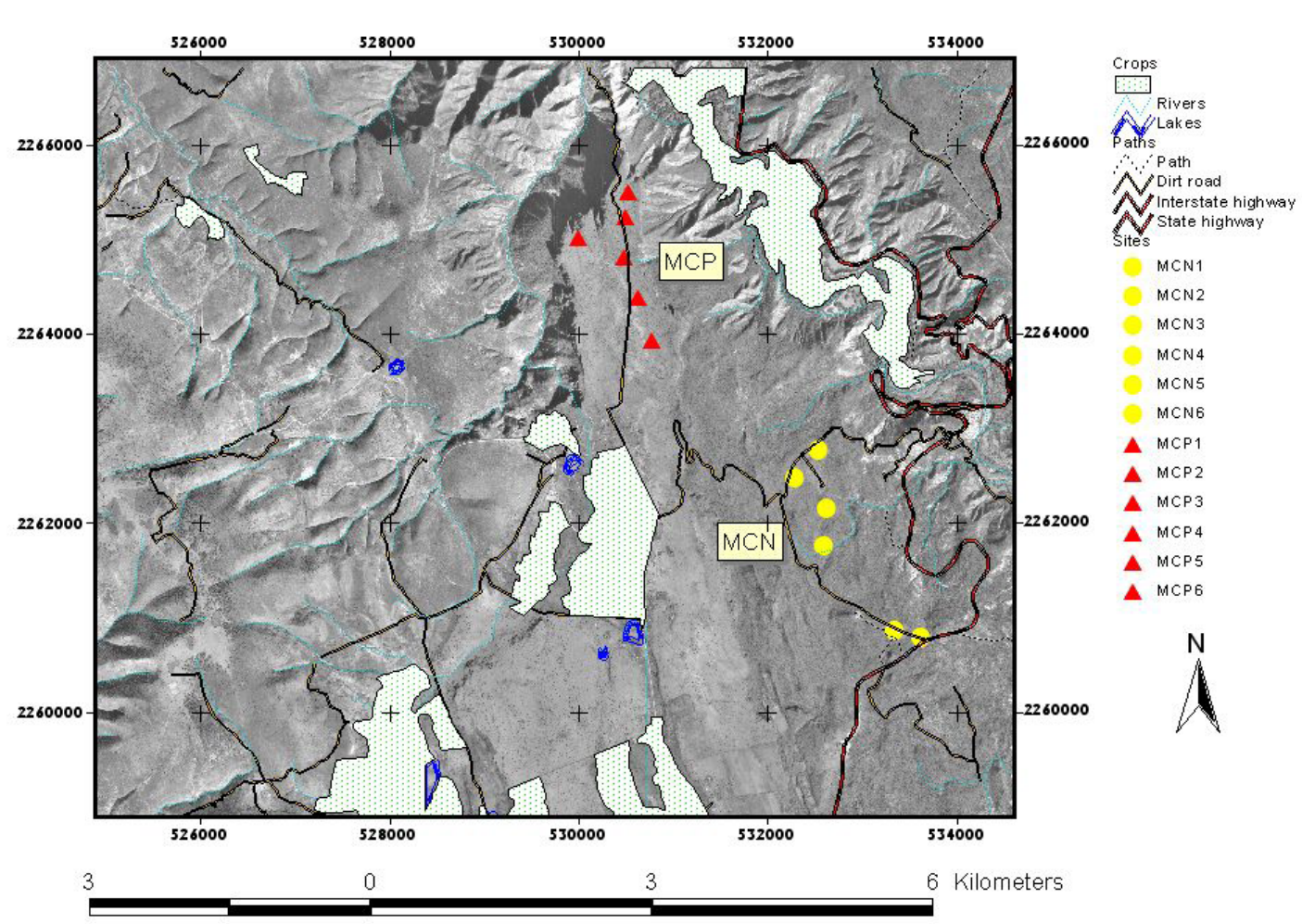

Mapa 1. Ubicación espacial de los puntos de muestreo dentro del matorral crasicaule, los puntos amarillos corresponden al matorral natural $(\mathrm{MCN})$ y los triángulos rojos al matorral perturbado (MCP). 
Todas las especies aquí incluidas han sido recogidas como larvas o pupas en los tejidos de cactáceas en descomposición y posteriormente criadas en el laboratorio hasta su nacimiento en el mismo sustrato en el que fueron encontradas (Tabla 1). Los datos de campo pueden ser consultados en Moreno et al., 2007 y Martínez Falcón et al., 2001a. En todos los casos se anotó su planta de procedencia y la duración de las diferentes fases de su ciclo biológico. Como resultado de este estudio se criaron 3821 ejemplares de Copestylum pertenecientes a doce especies durante los dos ańos de muestreo (Moreno et al., 2007; Martínez-Falcón et al., 2011; Rotheray et al., 2009). Todas las fotos de la clave fueron realizadas por las autoras.

\begin{tabular}{|c|c|c|}
\hline Especie & Grupo & Planta hospedera \\
\hline $\begin{array}{c}\text { C. hidalgense } \\
\text { (Marcos \& Rotheray, 2009) }\end{array}$ & Apiciferum & $\begin{array}{l}\text { Isolatocereus dumortieri (Scheidw) } \\
\text { Backeb., Opuntia ficus-indica (L.) Mill., } \\
\text { Cylindropuntia tunicata (Lech) F.M. } \\
\text { Knuth. }\end{array}$ \\
\hline $\begin{array}{c}\text { C. latum } \\
\text { (Wiedemann, 1830) }\end{array}$ & Isabellina & $\begin{array}{l}\text { Isolatocereus dumortieri (Scheidw) } \\
\text { Backeb., Myrtillocactus geometrizans } \\
\text { (Mart. ex Pfeiff.) Console, Opuntia } \\
\text { ficus-indica (L.) Mill. }\end{array}$ \\
\hline $\begin{array}{l}\text { C. limbipenne } \\
\text { (Williston, 1887) }\end{array}$ & Marginatum & $\begin{array}{l}\text { Isolatocereus dumortieri (Scheidw) } \\
\text { Backeb., Myrtillocactus geometrizans } \\
\text { (Mart. ex Pfeiff.) Console, Opuntia } \\
\text { ficus-indica (L.) Mill }\end{array}$ \\
\hline $\begin{array}{l}\text { C. marginatum } \\
(\text { Say, 1829) }\end{array}$ & Marginatum & $\begin{array}{l}\text { Isolatocereus dumortieri (Scheidw) } \\
\text { Backeb., Myrtillocactus geometrizans } \\
\text { (Mart. ex Pfeiff.) Console., } \\
\text { Opuntia ficus-indica (L.) Mill, } \\
\text { Echinocereus cinerascens (DC.) Lem., } \\
\text { Cylindropuntia tunicata (Lech) F.M. } \\
\text { Knuth. }\end{array}$ \\
\hline $\begin{array}{l}\text { C. mexicanum } \\
\text { (Macquart, 1842) }\end{array}$ & Dispar & Opuntia ficus-indica (L.) Mill \\
\hline $\begin{array}{c}\text { C. milae } \\
\text { (Marcos \& Rotheray, 2009) }\end{array}$ & Apiciferum & $\begin{array}{l}\text { Isolatocereus dumortieri (Scheidw) } \\
\text { Backeb. }\end{array}$ \\
\hline $\begin{array}{l}\text { C. posticum } \\
\text { (Say, 1829) }\end{array}$ & Isabellina & $\begin{array}{l}\text { Isolatocereus dumortieri (Scheidw) } \\
\text { Backeb., Myrtillocactus geometrizans } \\
\text { (Mart. ex Pfeiff.) Console, Opuntia } \\
\text { ficus-indica (L.) Mill, Echinocereus } \\
\text { cinerascens (DC.) Lem. }\end{array}$ \\
\hline $\begin{array}{c}\text { C. sica } \\
\text { (Curran, 1953) }\end{array}$ & Dispar & $\begin{array}{c}\text { Isolatocereus dumortieri (Scheidw) } \\
\text { Backeb, Echinocereus cinerascens (DC.) } \\
\text { Lem. }\end{array}$ \\
\hline $\begin{array}{c}\text { C. simile } \\
\text { (Giglo-Tos, 1892) }\end{array}$ & Marginatum & $\begin{array}{l}\text { Isolatocereus dumortieri (Scheidw) } \\
\text { Backeb, Myrtillocactus geometrizans } \\
\text { (Mart. ex Pfeiff.) Console, Opuntia } \\
\text { ficus-indica (L.) Mill }\end{array}$ \\
\hline
\end{tabular}




\begin{tabular}{c|c|c}
\hline $\begin{array}{c}\text { C. tetetzoi } \\
\text { (Marcos, Hancock \& Rotheray, } \\
\text { 2009) }\end{array}$ & Marginatum & $\begin{array}{c}\text { Isolatocereus dumortieri (Scheidw) } \\
\text { Backeb. }\end{array}$ \\
\hline $\begin{array}{c}\text { C. truncatum } \\
\text { (Marcos, Hancock \& Rotheray, } \\
\text { 2009) }\end{array}$ & Marginatum & $\begin{array}{c}\text { Isolatocereus dumortieri (Scheidw) } \\
\text { Backeb, Opuntia ficus-indica (L.) Mill }\end{array}$ \\
\hline $\begin{array}{c}\text { C. violaceum } \\
\text { (Say, 1829) }\end{array}$ & Dispar & $\begin{array}{c}\text { Isolatocereus dumortieri (Scheidw) } \\
\text { Backeb., Opuntia ficus-indica (L.) Mill }\end{array}$ \\
\hline
\end{tabular}

Tabla 1. Especies del género Copestylum Macquart, 1846 cuyas larvas se desarrollan en especies de cactáceas en descomposición en la reserva de la biosfera Barranca de Metztitlán

\section{CLAVE DE ADULTOS DE LAS ESPECIES DE COPESTYLUM QUE SE DESARRO- LLAN EN LAS CACTÁCEAS DE LA RE- SERVA DE LA BIOSFERA "BARRANCA DE METZTITLÁN" (HIDALGO, MÉXICO)}

1. Arista antenal con densa setosidad dispuestas a modo de pluma (Fig. 1A). . .2

- Arista antenal con setas largas y poco abundantes (Fig. 1B) .3

2. Ala hialina o ligeramente oscurecida en el centro (Fig.2A).

- Ala con evidentes manchas oscuras en su membrana (Fig. 2B).

3. Ala muy oscurecida en su parte basal (Fig. 3A)

- Ala completamente hialina o con manchas oscuras en posición variable, pero nunca en su parte basal (Figs. 2A y 3B)

4. Esternitos abdominales completamente negros (Fig. 4A); banda facial mediana levemente oscurecida en su parte inferior (Fig. 4B); mesonoto y escudete de la hembra con setas cortas. .C. simile (Fig.4C)

- Esternitos abdominales parcialmente pálidos; banda facial mediana conspicua y alcanzando la base de la antena (Fig. 4D). . .5

5. Manchas pálidas preescutelares de anchura menor a la distancia que las separa (Fig. 5A); machos con frente negra. .C. marginatum (Fig. 5B)
- Manchas pálidas preescutelares de anchura superior a la distancia que las separa (Fig. 5C); frente de los machos de color negro y amarillo C. tetetzoi (Fig. 5D)

6. Frente de color amarillo, alas con manchas oscuras en su centro..... C. truncatum (Figs. 6A y 6B)

- Alas con su margen anteroapical oscuro y con abundantes microtrichias.......C. limbipenne (Figs. 7A y 7B)

7. Álula oscurecida por la presencia de microtrichias (pequeñas setas) en toda su extensión (Fig. 8A). C. mexicanum (Fig. 8B)

- Álula lampiña, al menos en su tercio distal (Fig. 8C) (hembras no fácilmente distinguibles de especies afines)......

8. Machos: surstylus romo apicalmente, lóbulo superior del hypandrium con una pequeña espina dorsobasal (Fig. 9A)......... . violaceum (Fig. 9B)

- Surstylus agudo en su extremo apical, lóbulo superior del hypandrium con presencia de espina dorsobasal (Fig. 9C).....C. sica (Fig. 9D)

9. Margen lateral del mesonoto con setas negras; algunas setas negras y gruesas en el centro del área preescutelar (Fig. 10). 10

- Margen lateral del mesonoto principalmente con setas pálidas; con algunas setas negras aisladas; área preescutellar sin setas negras; álula prácticamente desnuda .11 
10. Álula prácticamente lampiña, sólo microtrichias en su parte basal..........C. latum (Fig. 11)

- Álula completamente cubierta de microtrichias; mesonoto negro brillante (Fig. 12A); abdomen oscuro o negro, usualmente con iridiscencias púrpura (Fig.12B)

C. posticum (Fig. 12C)

11. Tercer segmento antenal oscuro (Fig. 13A); banda facial mediana no alcanzando la base de la antena; ojos cubiertos de setas negras C. hidalgense (Figs. 13B y 13C)

- Tercer segmento antenal amarillo (Fig. 14A); banda facial mediana ausente (Fig. 14B); ojos con setas amarillas; escudete con setas amarillas y una banda transversal de setas negras; ojos de los machos con un área dorsal de facetas de mayor tamaño (Fig. 14C).........C. milae (Fig. 14D)

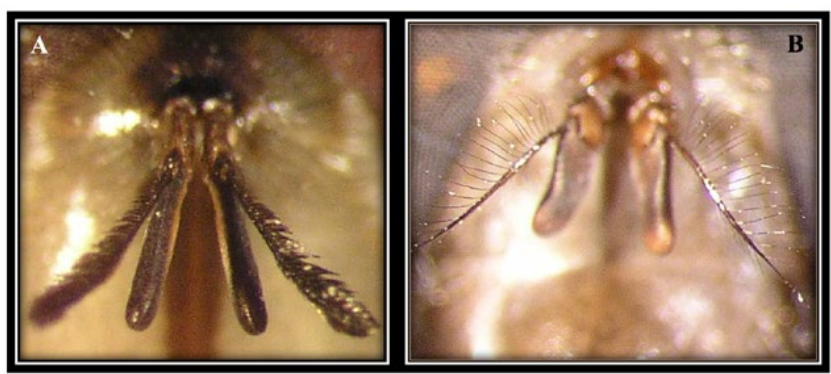

Figura 1. A) Arista antenal densamente plumosa ( $C$. marginatum) y B) Arista antenal con setas largas y menos abundantes (C. cockerelli)
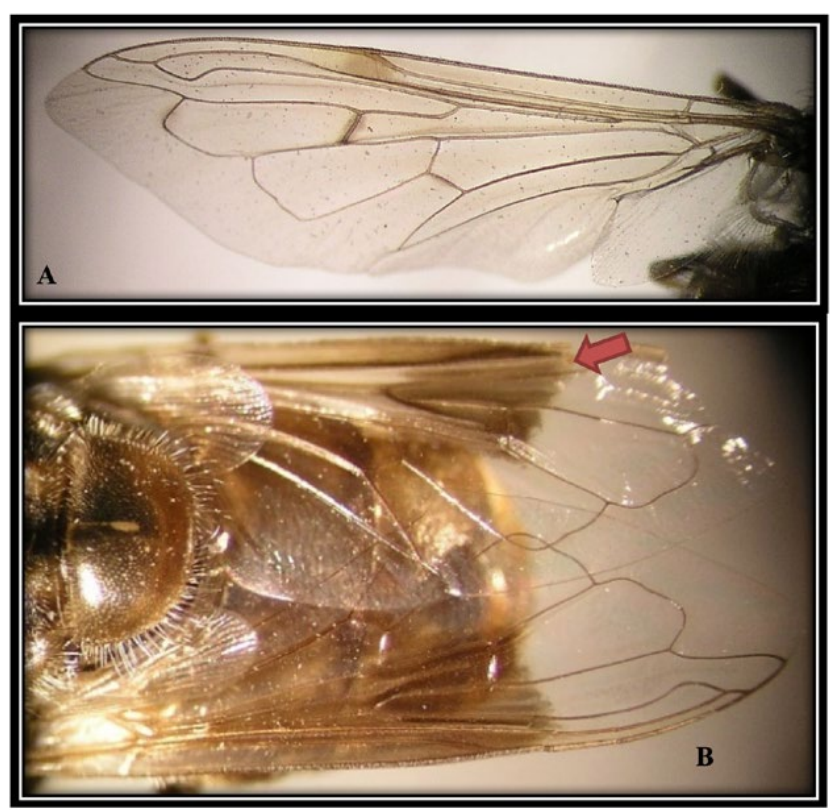

Figura 2. A) Ala hialina (C. simile) y B) Ala con manchas oscuras en su membrana (C. becquarti).

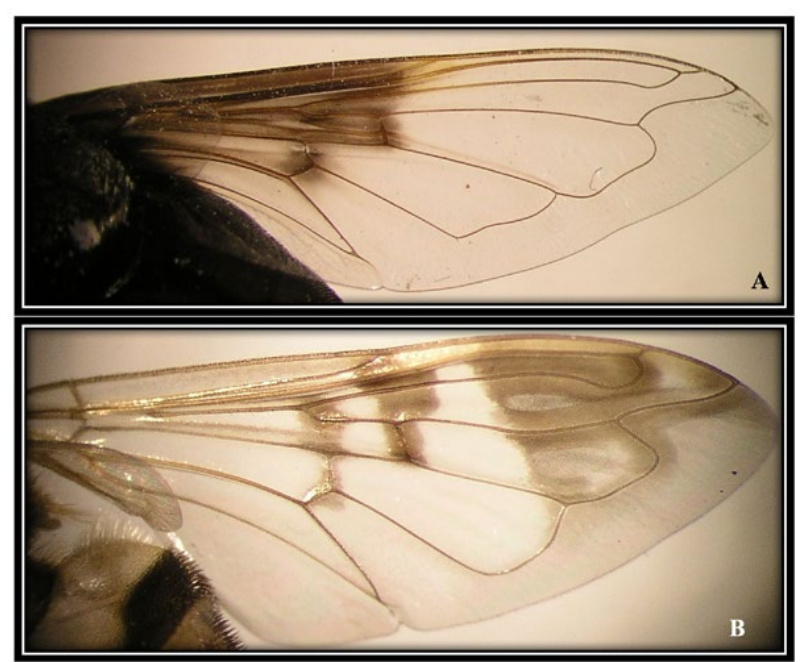

Figura 3. A) Ala oscurecida en su parte basal (C. violaceum) y B) Ala con manchas oscuras en posición variable (C. imitans).

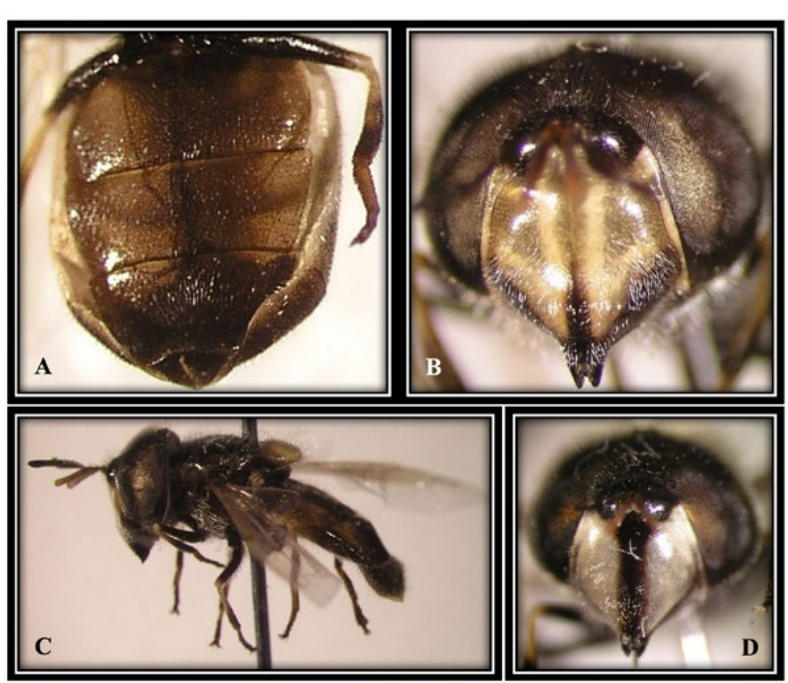

Figura 4. A) Esternitos abdominales completamente oscuros, B) banda facial levemente oscurecida (C. simile), C) Copestylum simile, vista lateral del cuerpo, y D) Banda facial mediana conspicua y alcanzando la base antenal (C. marginatum). 


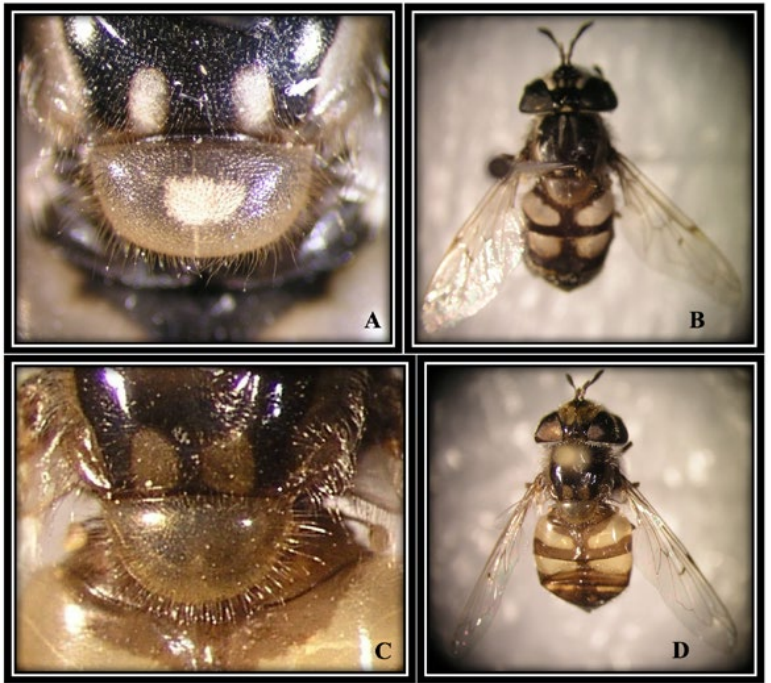

Figura 5. A) Manchas preescutelares estrechas y ampliamente separadas (C. marginatum), B) Copestylum marginatum, C) Manchas preescutelares más anchas y cercanas entre sí (C. tetetzoi) y D) Copestylum tetetzoi.
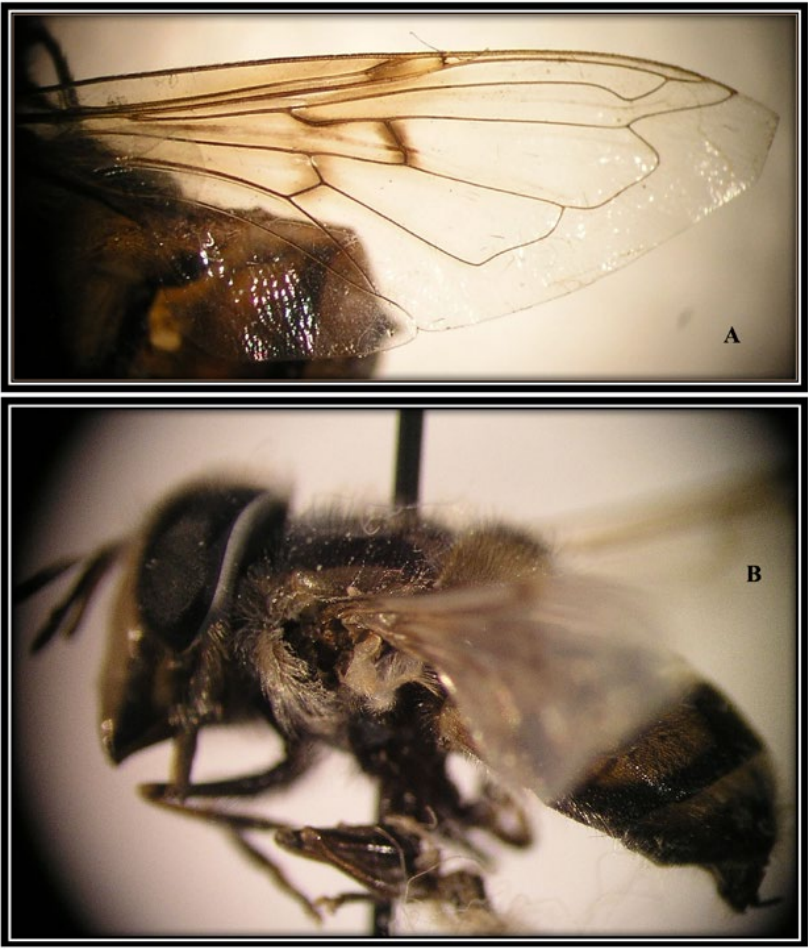

Figura 6. A) Alas con manchas oscuras en su centro ( $C$. truncatum) y B) Copestylum truncatum.

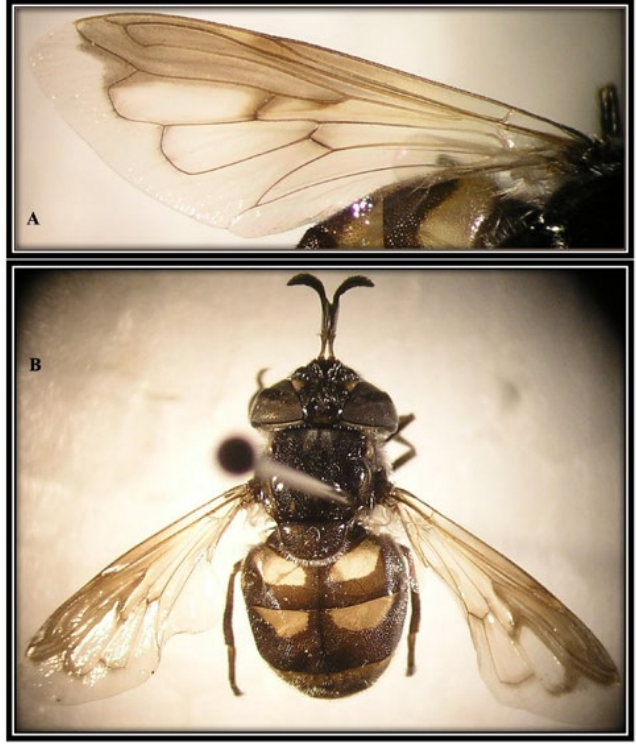

Figura 7. A) Alas con el margen anteroapical oscuro ( $C$. limbipenne) y B) Copestylum limbipenne.

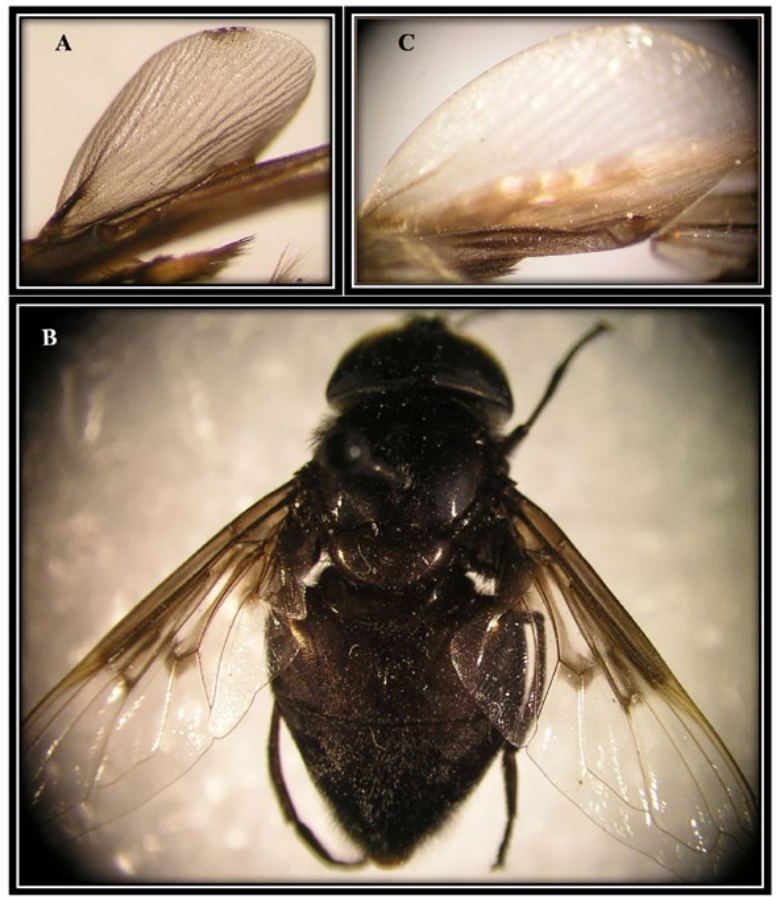

Figura 8. A) Álula oscura, cubierta por microtrichia en toda su extensión (C. macrocephalum), B) Copestylum mexicanum y C) Álula parcialmente desnuda (C.latum). 


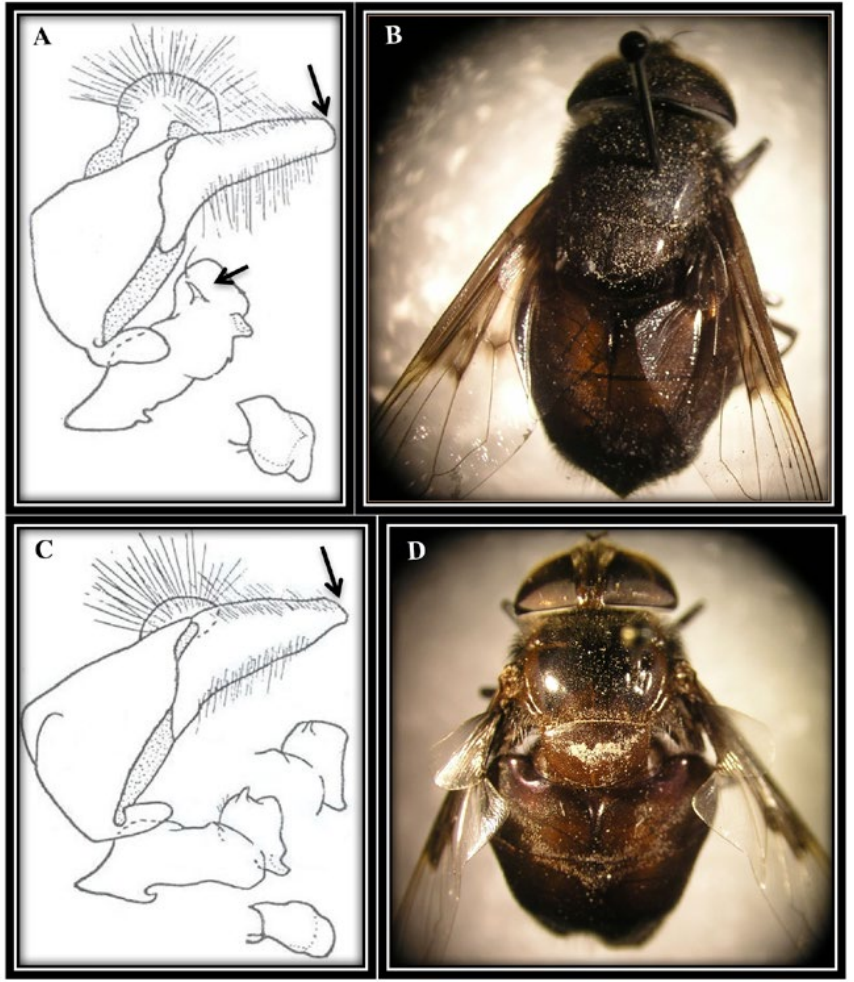

Figura 9. A) Surtylus romo apicalmente, B) Copestylum violaceum, C) Surstylus agudo en su extremo apical y D) Copestylum sica

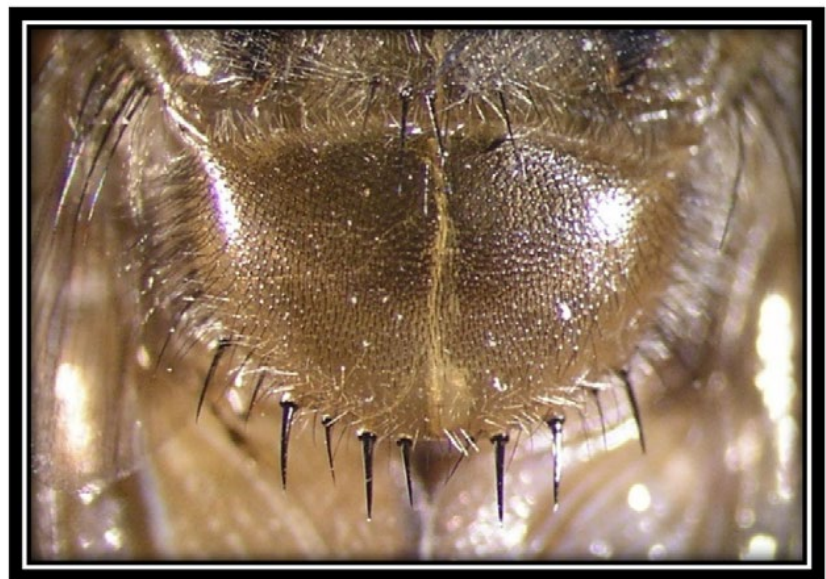

Figura 10. Mesonoto con setas negras y gruesas en el centro del área preescutelar (C. cockerelli)

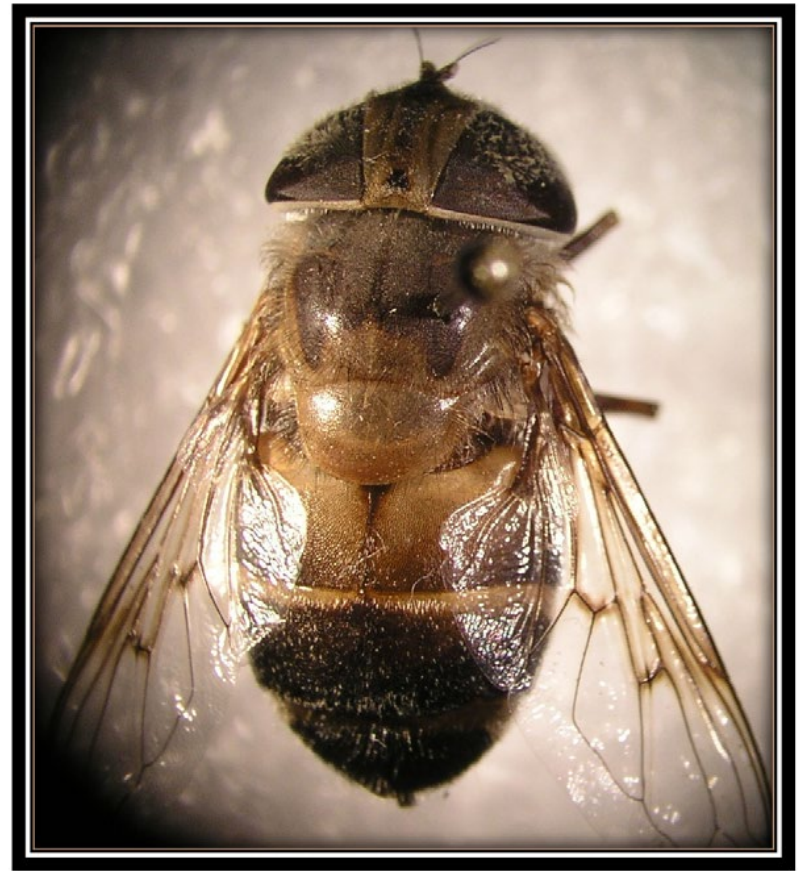

Figura 11. Copestylum latum
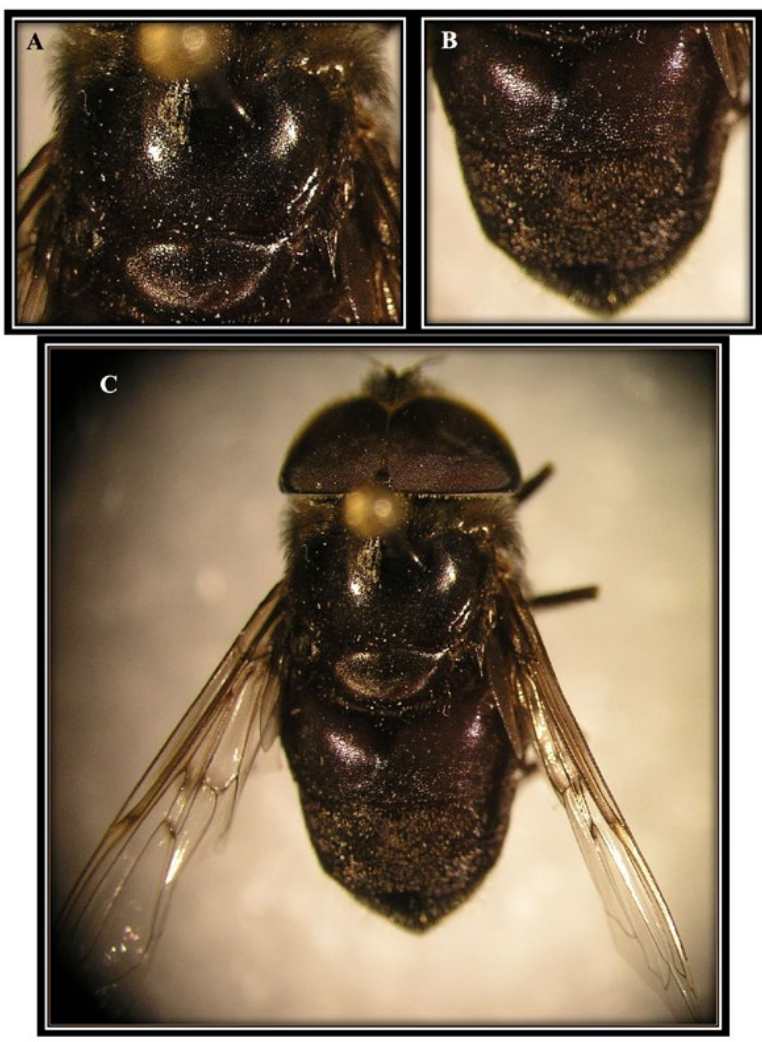

Figura 12. A) Mesonoto negro brillante (C. posticum), B) Abdomen completamente negro (C. posticum) y C) Copestylum posticum. 

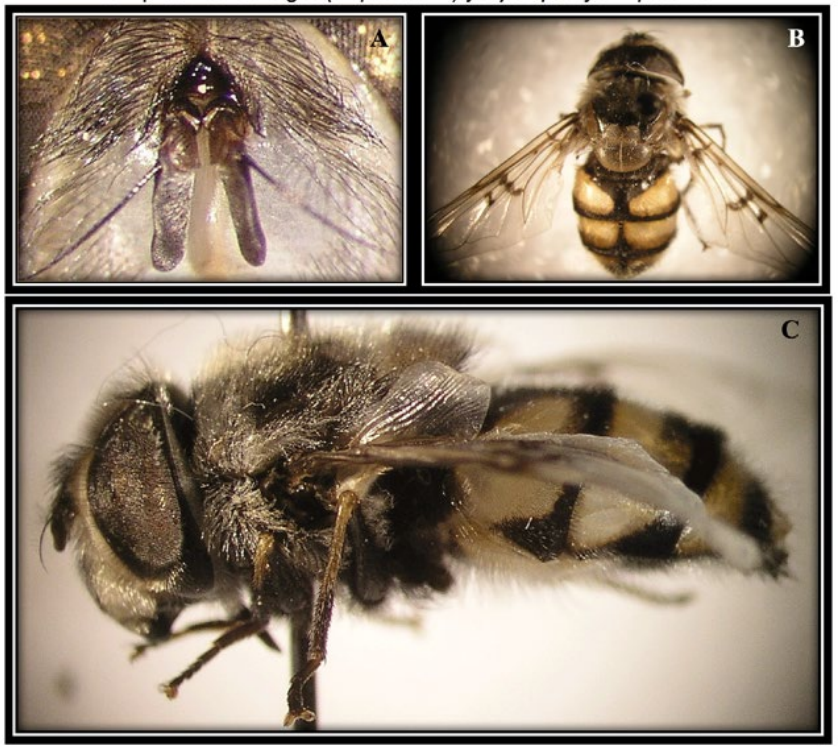

Figura 13. A) Tercer segmento antenal oscuro (C. hidalgense), B) Copestylum hidalgense (dorsal) y C) Copestylum hidalgense (lateral).

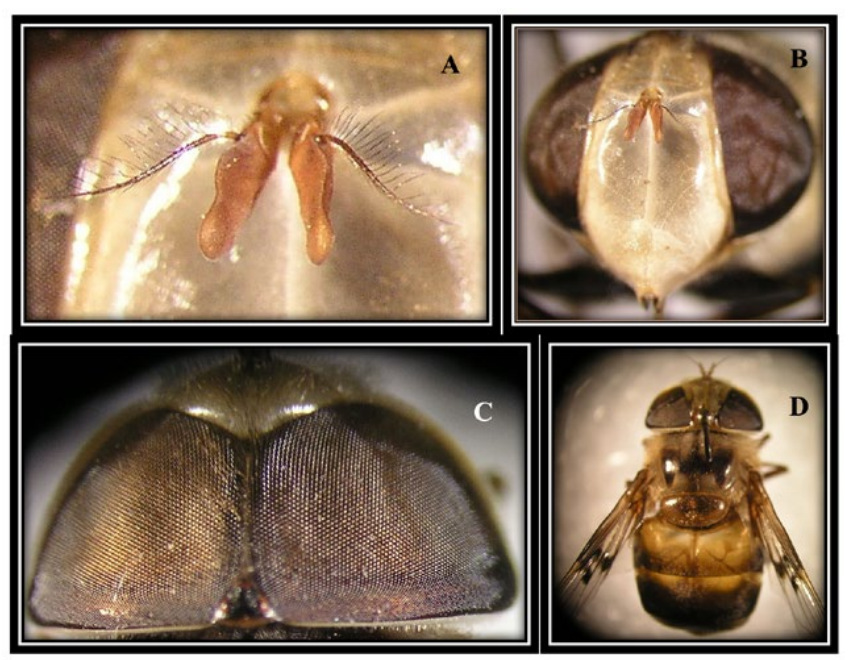

Figura 14. A) Tercer segmento antenal pálido (C. milae), B) Banda facial mediana ausente (C.milae), C) Ojos de los machos con un área dorsal de facetas de mayor tamaño y D) Copestylum milae.
Como resultado del trabajo de campo detallado en Moreno et al., (2007) y Martínez-Falcón et al. (2011a), se registraron por vez primera 12 especies de Copestylum pertenecientes a 4 grupos para la reserva de la biosfera "Barranca de Metztitlán", Una de estas especies, Copestylum hidalgense, resultó ser nueva para la ciencia, y hasta el momento solo es conocida, y en escaso número de individuos, de esta reserva biológica. Esta especie fue descrita en Rotheray et al., (2009) y sus larvas se desarrollan en las cactáceas Cylindropuntia tunicata (Lehm) F.M. Knuth e Isolatocereus dumortieri. Gracias a este estudio, fue también posible describir por vez primera los estados inmaduros y la planta huésped de Copestylum milae (Rotheray et al., 2009).

Se corroboró también la abundancia de Copestylum marginatum en la parte central de México y en tejido en descomposición de la cactácea Opuntia. Se constata la abundancia durante todo el año de las larvas de dos especies de gran tamaño, Copestylum latum y Copestylum posticum, aunque son especialmente abundantes en el periodo de lluvias. En cuanto a las especies de menor tamaño, Copestylum marginatum, Copestylum simile, Copestylum limbipenne y Copestylum truncatum, presentaron alta abundancia, tanto en los medios naturales como en los perturbados por la ganadería, produciéndose en general un recambio estacional en la composición numérica de estas especies. Esta información puede ser contrastada en Moreno et al. (2007) y MartínezFalcón et al. (2011).

Gracias a este estudio se registraron 12 especies de Copestylum en esta Reserva de la Biosfera cuyas larvas viven en los tejidos en descomposición de las cactáceas allí presentes y se facilita la identificación de los adultos, potenciales protagonistas de la acción polinizadora en la Barranca. 


\section{REFERENCIAS}

Bravo-Hollis, H. (1978). Las cactáceas de México. Vol.1, $2^{\text {a }}$ ed. Universidad Nacional Autónoma de México, México. D.f.

Marcos-García, M.A. \& Pérez-Bañón C. (2002). Life cycle, adult and immature stage of a new species of Copestylum (Diptera:Syrphidae) from Mexico reared from Cactaceae. Annals of the Entomological Society of America, 95(4):432440.

Martínez-Falcón, A.P., Marcos-García, M.A. \& Moreno, C. (2011a). Temporal shifts and niche overlapping shifts and niche overlapping in Copestylum (Diptera, Syrphidae) communities reared in cactus species in a central Mexican scrubland. Ecological Research, 26:341-350.

Martínez-Falcón, A.P., Marcos-García, M.A., Díaz-Castelazo, C. \& Rico Gray., V. (2010). Seasonal changes in a cactus-hoverfly (Diptera: Syrphidae) network. Ecological Entomology, 35:754-759.

Martínez-Falcón, A.P., Marcos-García, M.A., Moreno C. \& Rotheray (2012). A critical role for Copestylum larvae (Diptera, Syrphidae) in the decomposition of cactus forests. Journal of Arid Environments, 78:41-48.

Martínez-Falcón, A.P., Durbán, A., Latorre, A., Antón, J. \& Marcos-García, M.A. (2011b). Bacteria associated to Copestylum (Diptera, Syrphidae) larvae and their host breeding cactus. PLoS ONE 6(11): e27443. doi:10.1371/ journal.pone.0027443
Moreno, C.E., Sánchez-Rojas, G., Verdú, J.R., Numa, C., Marcos-García, M., Martínez-Falcón, A. P., Galante, E. \& Halffter, G. (2007). Biodiversidad en ambientes agropecuarios semiáridos en la Reserva de la Biosfera Barranca de Metztitlán, México. En Halffter, G., Guevara, S. \& Melic, A. (eds.), Hacia una cultura de conservación de la diversidad biológica. Zaragoza: Monografías Tercer Milenio pp. 97-107.

Ricarte, A., Marcos-García, M.Á., Hancock, E.G. \& Rotheray, G.E. (2015). Neotropical Copestylum Macquart (Diptera: Syrphidae) breeding in fruits and flowers, including 7 new species. PloS one, 10(11): e0142441.

Rotheray, G.E., Hancock, G. \& Marcos-García, M.A. (2007). Neotropical Copestylum (Diptera, Syrphidae) breeding in bromeliads (Bromeliaceae) including 22 new species. Zoological Journal of the Linnean Society 150(2), 267-317.

Rotheray, G.E., Marcos-García, M.A., Hancock, G., PérezBañon, C. \& Maier, C.T. (2009). Neotropical Copestylum (Diptera, Syrphidae) breeding in Agavaceae and Cactaceae including seven new species. Zoological Journal of the Linnean Society, 156(4):697-749.

Thompson, F.C. (1999). A key to the genera of the flower flies (Diptera: Syrphidae) of the Neotropical Region including descriptions of new genera and species and a glossary of taxonomic terms. Contributions on Entomology, International.3: 321-378. 
Este número ha recibido una ayuda del Vicerrectorado de Investigación y Transferencia de Conocimiento de la Universidad de Alicante
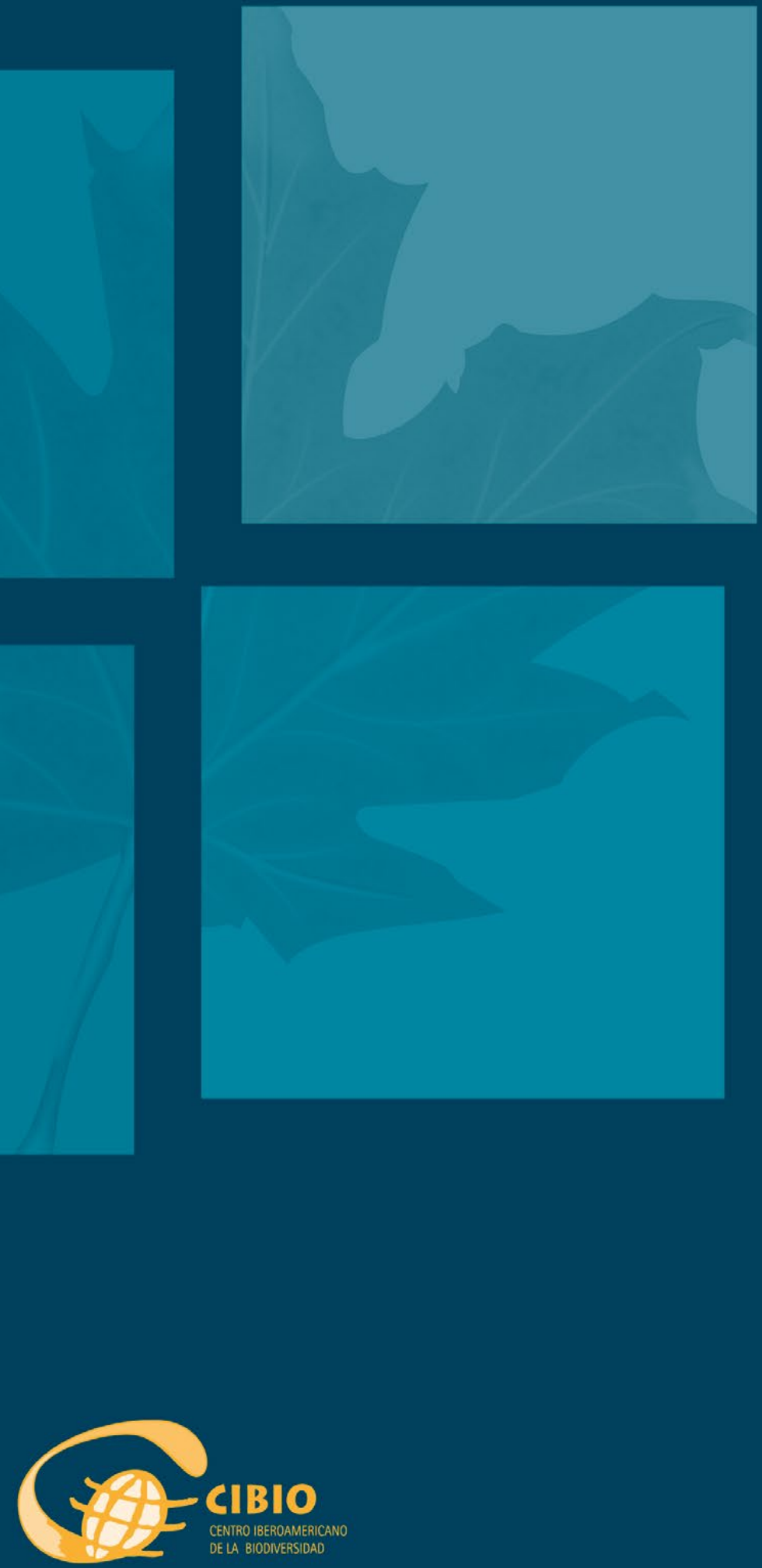

\section{Universitat d'Alacant
Universidad de Alicante}

